\title{
A EDUCAÇÃO PROFISSIONAL TÉCNICA DE NÍVEL MÉDIO EM SAÚDE NA REDE FEDERAL DE EDUCAÇÃO
}

\author{
MIDDLE LEVEL PROFESSIONAL TECHNICAL EDUCATION IN HEALTH IN THE FEDERAL EDUCATION \\ NETWORK
}

LA EDUCACIÓN PROFESIONAL TÉCNICA DE NIVEL MEDIO EN SALUD EN LA RED FEDERAL DE EDUCACIÓN

\author{
Anderson Boanafina ${ }^{1}$ \\ Lilian Boanafina ${ }^{2}$ \\ Mônica Wermelinger ${ }^{3}$
}

Resumo A educação profissional precisa ser pensada e implementada como uma ação estratégica, considerando as potencialidades tecnológicas locais e regionais, realçando sua interação com o mundo do trabalho e, fundamentalmente, com a sociedade local, com a função primordial de formação cidadã e preparando o jovem para ser agente ativo nos processos de desenvolvimento social, econômico e cultural. A partir dessa premissa, o presente artigo propôs uma análise das matrículas na educação profissional, destacando-se dados e informações relevantes para a compreensão do atual cenário da formação de recursos humanos na área da saúde promovida por instituições federais no Brasil. O estudo aponta um aparente descolamento entre as políticas de expansão da rede federal de educação profissional na área da saúde e as demandas do Ministério da Saúde para suprir a carência de profissionais de nível médio em saúde, especialmente nas regiões Norte, Nordeste e Centro-Oeste e, particularmente, fora dos grandes centros urbanos.

Palavras-chave educação profissional; instituições federais; saúde.
Abstract Professional education needs to be considered and implemented as a strategic move, considering local and regional technological potential, enhancing their interaction with the labor world and, fundamentally, with the local community, with the primary function of citizen training and preparing the youth to be active agents in the social, economic, and cultural development processes. Based on this premise, this paper proposes an analysis of enrollment in professional education, especially data and information relevant to understanding the current scenario of the training of human resources in health promoted by federal institutions in Brazil. The study shows an apparent detachment between the federal vocational education network expansion policies in the health area and the Ministry of Health's needs to address the lack of mid-level health professionals, especially in the North, Northeast and Midwest, and particularly outside of the major urban centers.

Keywords professional education; federal institutions; health. 


\section{Introdução}

O rápido avanço dos processos de urbanização e desenvolvimento tecnológico vem promovendo a ruptura de fronteiras geográficas e culturais. Contudo, de forma antagônica, os mesmos processos estão ampliando a distância entre os incluídos e os excluídos socialmente. Percebe-se que, enquanto o acesso à educação profissional se torna, a cada dia, mais decisório para a inserção dos jovens e adultos no mundo produtivo, para a população que vive distante dos grandes centros urbanos esse acesso permanece difícil, geralmente pela falta de instituções de ensino em suas regiões.

A complexidade que permeia a formação profissional fortalece as possibilidades de articulação dos conhecimentos oriundos da prática social aos conhecimentos científicos, aliando os conteúdos gerais aos específicos de qualificação, de modo a construir uma nova forma de responder às demandas sociais, combater a exclusão social e promover o desenvolvimento das ciências e de modernas tecnologias. Os crescentes investimentos públicos, visando à expansão da rede de ensino profissional (em especial da federal), estão associados, na atualidade, ao momento de transição entre o ensino direcionado ao simples 'fazer' para uma educação estruturada no 'saber-pensar', produzindo desafios tanto para os programas pontuais de formação inicial para o trabalho quanto para os programas de atualização científica e tecnológica.

$\mathrm{Na}$ área de saúde, se comparada a outras áreas de formação, torna-se peculiar a análise do comportamento das matrículas, da expansão dos estabelecimentos e, essencialmente, da qualidade do ensino ministrado, em especial por seu papel social, simbolizado na preservação da vida e do bem-estar do indivíduo. Outro aspecto que diferencia e qualifica a análise da expansão de matrículas na área da saúde é sua relevância suprarregional, tendo em vista que não há 'vocação regional' que justifique a concentração da oferta desses cursos em quaisquer regiões, uma vez que instituições de saúde e seus profissionais são demandas generalizadas da população.

Dessa forma, a presente investigação teve por objetivo mapear a contribuição da rede federal de educação profissional na formação de profissionais de nível médio para a área da saúde. Além disso, os resultados permitiram identificar, por região, a participação da rede formada pelas escolas federais e a oferta de cursos de educação profissional em saúde. Essas informações poderão subsidiar novos estudos que visem, também, ao fortalecimento das ações do Ministério da Saúde e das secretarias estaduais e municipais, apoiando o Sistema Único de Saúde (SUS) e os programas setoriais dos governos. 


\section{Percurso metodológico}

Nesse processo, para atingir os resultados ora apresentados, foram cumpridas diversas etapas, cabendo destacar o fato de que a investigação referenciou-se em um quadro teórico-metodológico que articulou: levantamento documental e bibliográfico sobre o tema; dados do Censo da Educação Básica do Ministério da Educação/Instituto Nacional de Estudos e Pesquisas Educacionais Anísio Teixeira (MEC/Inep)4 (1999 a 2014); o banco de dados do Instituto Brasileiro de Geografia e Estatística (IBGE) (Síntese de Indicadores Sociais); e informações dos relatórios e estudos setoriais (Agência Nacional de Saúde Suplementar (ANS); demografia médica no Brasil).

Ao longo desse percurso, foram compilados dados sobre a educação profissional nas 27 unidades federativas, ou 26 estados e o Distrito Federal, que compõem as cinco regiões do Brasil. Utilizaram-se documentos do MEC e do Conselho Nacional de Educação (CNE), tais como diretrizes, normas e legislação específica para a educação profissional, que, juntamente com a revisão bibliográfica e leituras específicas sobre a trajetória da educação profissional, com ênfase na área da saúde, subsidiaram a investigação em torno do assunto.

O desenho investigativo adotado foi do tipo descritivo, com base documental e análise quantitativa, com o objetivo de estruturar novas informações utilizando bancos de dados públicos sobre a distribuição da formação e atuação de profissionais de nível médio em saúde no território brasileiro de modo a construir uma série histórica, de 2001 a 2013, da expansão das matrículas na educação profissional em saúde no país e, em especial, dos cursos e instituições que faziam parte da rede federal de educação.

Os resultados obtidos pela investigação, doravante apresentados, poderão subsidiar importantes reflexões acerca da oferta de formação de profissionais da área de saúde no âmbito da educação profissional, servindo para auxiliar a tomada de decisões e procurando lançar luz sobre a necessidade de investimento localizado para a criação de novas escolas ou cursos técnicos, no âmbito da administração pública.

\section{Um breve histórico da educação profissional no Brasil}

A concepção de trabalho manual não era entendida, ainda no Brasil Colônia, como uma atividade de mérito social, e o seu conceito estava distante de ser algo vinculado à realização humana. Esta era associada, geralmente, às artes, ao comércio e às propriedades. Por conseguinte, aquele que realizava ou 
aprendia uma atividade produtiva manual carregava a marca negativa de ser uma pessoa sem riquezas ou de ser um (ex)escravo. Para Galeano (1987), esse cenário permitiu que, cada vez mais, os integrantes das classes sociais mais ricas se afastassem daqueles que integravam as classes mais pobres e esquecidas do país.

Em decorrência desse fato, os escravos e colonos pobres que dominavam técnicas, mesmo simples, de fabricação ensinavam seus conhecimentos nas próprias fazendas em rudimentares oficinas. Considerando que "a segregação social, a economia da época e a incipiente cultura reinante não permitiam, nem estavam a exigir outra forma de aprendizagem de ofícios" (Fonseca, 1961, p. 13-14) essa formação de trabalhadores ficou distinta, já no início, por terem sido os índios, os escravos e seus descendentes os primeiros aprendizes de ofícios. A formação do trabalhador trazia o estigma da servidão, pois "habituou-se o povo de nossa terra a ver aquela forma de ensino como destinada somente a elementos das mais baixas categorias sociais" (Fonseca, 1961, p. 68).

Essa concepção sobre o ensino, que podemos definir como culturalmente equivocada, destinada à formação de trabalhadores, influenciou reformas políticas e educacionais até meados da década de 1990, quando uma nova concepção de formação, direcionada à educação profissional, começou a ser traçada na Lei de Diretrizes e Bases da Educação (LDB) (Brasil, 1996).

Contudo, em perspectiva histórica, a educação profissional passou por diferentes concepções políticas e administrativas até a atual estrutura, variando do assistencialismo - caracterizado no decreto n. 7.566, de 23 de setembro de 1909 (Brasil, 1909), assinado pelo presidente Nilo Peçanha, criando 19 'escolas de aprendizes artífices' - e passando pelas ações compensatórias, no governo Vargas, até chegar ao modelo de formação profissional que busca associar a expansão da oferta de cursos profissionalizantes com as demandas sociais por emprego e geração de renda.

Para o entendimento da formação da rede federal de educação profissional, o período de Getúlio Vargas no poder, a partir da década de 1930, se tornou relevante, especialmente pelo lançamento de seu projeto industrial que viabilizou fortes mudanças no cenário da educação profissional no Brasil, impulsionando o aumento na demanda de formação de operários especializados e de quadros técnicos intermediários.

No primeiro governo Vargas, em 1937, com a reforma do Ministério da Educação e Saúde Pública - que passou a se chamar Ministério da Educação e Saúde -, foram criadas a Superintendência de Ensino Profissional e a Divisão do Ensino Industrial. Extinguiram-se as escolas de aprendizes e artífices, com a criação, em seus lugares, de liceus profissionais e do Liceu Nacional, que mais tarde passaria a se chamar Escola Técnica Nacional, na série de leis conhecidas como 'Reforma Capanema', na década de 1940, ainda no governo Vargas. 
Na visão dos autores deste artigo, a Reforma Capanema, em perspectiva histórica restrita ao ensino profissionalizante, foi o embrião da atual estrutura da rede federal de educação, pois o decreto n. 4.127, de 25 de fevereiro de 1942 (Brasil, 1942), transformou os liceus industriais em escolas industriais e técnicas, passando a oferecer formação profissional em nível equivalente ao do secundário. A reforma também contribuiu para ampliar a dualidade existente entre a formação para o trabalho, realizada pelas escolas técnicas, e a formação propedêutica para o ensino superior, feita pelas escolas secundárias.

$\mathrm{O}$ fato é que o Ministério do Trabalho, pressionado pelas indústrias e suas crescentes demandas por trabalhadores, buscava um ensino profissionalizante de curta duração, direcionado às demandas das indústrias - enquanto o Ministério da Educação e Saúde, na figura de Capanema, propunha uma formação mais humanista, semelhante à educação secundária mda época, porém respeitando as 'vocações' dos educandos (Schwartzman, Bomeny e Costa, 2000).

A partir da Reforma de Capanema, na prática, as escolas técnicas passaram a ter um duplo papel: preparar estudantes para ingressar no mundo do trabalho e para continuar os estudos superiores. Segundo Morales-Gomez e Moe (1989, tradução nossa), essa dupla função, por muitos anos, estaria contribuindo para diminuir as oportunidades para as novas ocupações e promovendo um afastamento progressivo entre as escolas técnicas e as preocupações de trabalhadores e empresários no tocante à formação profissional.

De fato, a qualidade do ensino ministrado nas escolas técnicas federais se destacava pela qualidade do corpo docente e da infraestrutura disponível para a formação dos futuros técnicos. Como consequência, as disputas acirradas por vagas nos cursos favoreciam os alunos provenientes das classes médias que, após a conclusão do curso profissional, disputavam vagas nas melhores universidades do país.

Meio século após a Reforma Capanema, o desenvolvimento industrial do país e a necessidade de formar especialistas e técnicos de diversos níveis imprimiram nova perspectiva na esfera da educação profissional. Como consequência, em 1978 o governo deu início à política de transformação de algumas escolas técnicas em centros federais de educação tecnológica (Cefets), tendo por objetivos: ministrar ensino de graduação e pós-graduação, visando à formação de professores e especialistas para o ensino de segundo grau e de formação de tecnólogos; ministrar ensino de segundo grau, com vistas à formação de auxiliares e técnicos industriais; promover cursos de extensão, aperfeiçoamento e especialização, objetivando a atualização profissional na área industrial; realizar pesquisas na área técnica industrial, estimulando atividades criadoras e estendendo seus benefícios à comunidade, mediante cursos e serviços.

Mesmo admitindo-se que as iniciativas entre os anos de 1930 e 1990 no campo do ensino médio, propedêutico ou profissionalizante tiveram seus 
méritos, elas serviram mais para dissimular a histórica dicotomia criada entre as modalidades de ensino e menos para atender às demandas sociais por uma escola eficiente na oferta de ensino de excelência, tanto para o curso propedêutico quanto para o profissionalizante.

O movimento mais forte e significativo em prol de mudanças no sistema educacional aconteceu durante o processo para a elaboração da Constituição Federal de 1988, que resultou na inserção, no corpo do texto constitucional, dos princípios que deveriam reger a educação nacional. Contudo, a nova LDB (Brasil, 1996), que regulamenta o funcionamento do sistema de ensino preconizado na Carta Magna, foi sancionada e promulgada após oito anos de intensos debates e numerosas concessões.

De acordo com a LDB, a educação profissional de nível técnico e o ensino médio passaram a ser orientados por dois eixos complementares: a formação do profissional com potencial de empregabilidade e a formação propedêutica regular. Esses dois eixos tinham por finalidade a formação do trabalhador para a construção de seu itinerário profissional em conformidade com seu projeto de vida, com base na polivalência, no enriquecimento de tarefas laborais na busca por uma qualidade de vida mais digna.

Autores como Kuenzer (2000) e Ramos (2001) destacam as grandes contradições da LDB, que em seu texto, ao dar um caráter de 'flexibilidade' à educação profissional, estaria mantendo e fortalecendo as diferenças sociais, uma vez que a qualificação profissional, ao possibilitar as condições mínimas necessárias para uma pessoa ingressar no mundo produtivo, reduziria os gastos do poder público ante uma

educação científico-tecnológica e sócio-histórica de qualidade para todos, condição necessária para o exercício de uma cidadania que compreende o direito universal de participar da produção de bens materiais, culturais e políticos (Kuenzer, 2000, p. 94).

A desarticulação entre o ensino médio e a formação profissional, por meio do decreto n. 2.208/1997 (Brasil, 1997) teria como consequência a seguinte fragmentação da formação do trabalhador:

O desdobramento dos dois tipos de ensino recriará, necessariamente, a coexistência de redes de ensino separadas, que funcionarão com base em premissas distintas: o sistema regular com uma perspectiva de preparação para a continuidade dos estudos em nível universitário, e o sistema profissional ancorado à lógica do mercado (Manfredi, 2002, p. 135).

Essa política pela fragmentação da educação profissional, como sinalizam Frigotto, Ciavatta e Ramos (2005a, 2005b), estava na substituição de uma política 
educacional que privilegiasse a formação integrada por uma que acolhesse as necessidades do mercado. Ao detectar a demanda da sociedade por uma reorganização, na forma de oferecimento da educação profissional mais articulada à educação básica, o Poder Executivo revogou decreto-lei n. 2.208/1997 e promulgou o decreto-lei n. 5.154/2004 (Brasil, 2004). Segundo os autores citados, esse novo decreto pode ser considerado 'híbrido', por resultar do embate entre as forças conservadoras, defensoras dos interesses do mercado, e as progressistas, comprometidas com as políticas socioeducacionais que privilegiam a formação integral do ser humano. Frigotto, Ciavatta e Ramos (2005b, p. 4) também afirmam: “Ou interpretamos o Decreto como um ganho político e, também, como sinalização de mudanças (...) ou será apropriado pelo conservadorismo, pelos interesses definidos pelo mercado".

Por imposição do cenário social brasileiro, especialmente a partir do final do século XX, a formação do trabalhador passou a requerer a 'educação' em vez da simples qualificação, ou seja: o 'saber-fazer' deixou de ser suficiente, sendo necessário um conjunto de 'saberes' - que envolvesse, além da aprendizagem de técnicas, o desenvolvimento de comportamentos inter e intrapessoais. Segundo Deluiz (1996):

O trabalho já não pode ser pensado a partir da perspectiva de um determinado posto, mas de famílias de ocupações que exigem competências semelhantes aos trabalhadores.

Não se trata mais, portanto, de uma qualificação formal/qualificação prescrita/qualificação do trabalhador para desenvolver tarefas relacionadas a um posto de trabalho, definida pela empresa para estabelecimento das grades salariais, ou pelos sistemas de formação para certificação ou diplomação, onde as tarefas estavam descritas, codificadas e podiam ser visualizadas, mas da qualificação real do trabalhador, compreendida como um conjunto de competências e habilidades, saberes e conhecimentos, que provêm de várias instâncias, tais como, da formação geral (conhecimento científico), da formação profissional (conhecimento técnico) e da experiência de trabalho e social (qualificações tácitas) (Deluiz, 1996, p. 18).

Destaca-se também que a própria definição da função social da educação profissional ainda é um processo em construção e constante mudança, permeado por contradições e antagonismos e que necessita de mais debates envolvendo a sociedade. Na análise de textos legais e de reflexões de autores após a promulgação da LDB, pode-se perceber que são três importantes dimensões do ideário de formação profissional que influenciam fortemente a formulação de políticas para o setor, em termos de direcionalidade, conteúdo e abrangência:

A conceitual: o 'ensino profissional' deixa de ser um ensino de técnicas e passa a ter uma concepção de educação profissional e tecnológica; assim, 
busca articular o ensino à pesquisa, focando na formação de profissionais mediante a construção de conhecimentos com bases conceituais nas ciências, tecnologias e inovação;

A organizacional: ao se tornar uma modalidade de educação presente na formação inicial, no ensino médio e no ensino superior, e articulando-se nas diferentes modalidades de ensino, o ensino profissional passa a assumir um papel estratégico para o desenvolvimento nacional, atuando de forma pluralista, regionalizada e descentralizada, podendo ser ofertado, em qualquer nível, tanto pela iniciativa privada quanto por qualquer ente da federação (respeitada a legislação vigente);

A social: a educação profissional como direito social passa a fazer parte da agenda nacional, objetivando "garantir ao cidadão o direito ao permanente desenvolvimento de aptidões para a vida produtiva e social", conforme o art. $1^{\circ}$ da resolução CEB n. 4, de 1999 (Conselho Nacional de Educação, 1999a, 1999b).

Destarte, se as transformações sociais, principalmente no século XX, estiveram associadas a uma mudança na concepção de trabalho e esta à de educação, no início do século XXI as mudanças ocorreram na concepção de educação profissional, que passou a responder às demandas sociais por emprego e geração de renda, sendo estruturada pela busca da qualidade de vida e do desenvolvimento sustentável das regiões.

As definições das políticas públicas que regem a educação profissional preveem a compreensão das necessidades específicas de cada região, não sendo mais possível a replicação de modelos de instituição ou de cursos sem uma avaliação contextual. E como consequência da expansão de vagas e escolas, vem sendo consolidada, cada vez mais, a necessidade de se identificarem os fatores que contribuem para os 'sucessos' e as 'limitações' dessa expansão.

\section{A expansão da educação profissional e seus novos desafios}

A evolução das matrículas demonstrou o quanto, na última década, as políticas educacionais vêm ganhando visibilidade na agenda política e social no Brasil, focando, principalmente, a reorientação e a produção de avanços nos marcos regulatórios para a educação profissional.

Em 2001, existiam no Brasil 2.334 instituições que ofereciam cursos de educação profissional de nível médio. Em 2013, observou-se um relevante crescimento, passando para 5.261 estabelecimentos públicos (federais, estaduais e municipais]) e privados (particulares, confessionais, comunitários e filantrópicos). Esses números revelaram um aumento significativo das redes e, consequentemente, do número de matrículas. Em números absolutos, passou-se dos cerca de 462 mil alunos matriculados em 2001 para 1,44 milhão de ma- 
trículas em 2013, considerando as formas integrada, concomitante e subsequente para os cursos de educação profissional, segundo dados divulgados pelo Inep (Brasil, 2014a) (Gráfico 1).

Gráfico 1

Número de matrículas na educação profissional de nível nédio em instituições públicas e privadas (2001 a 2013) - modalidades: concomitante, subsequente e integrada

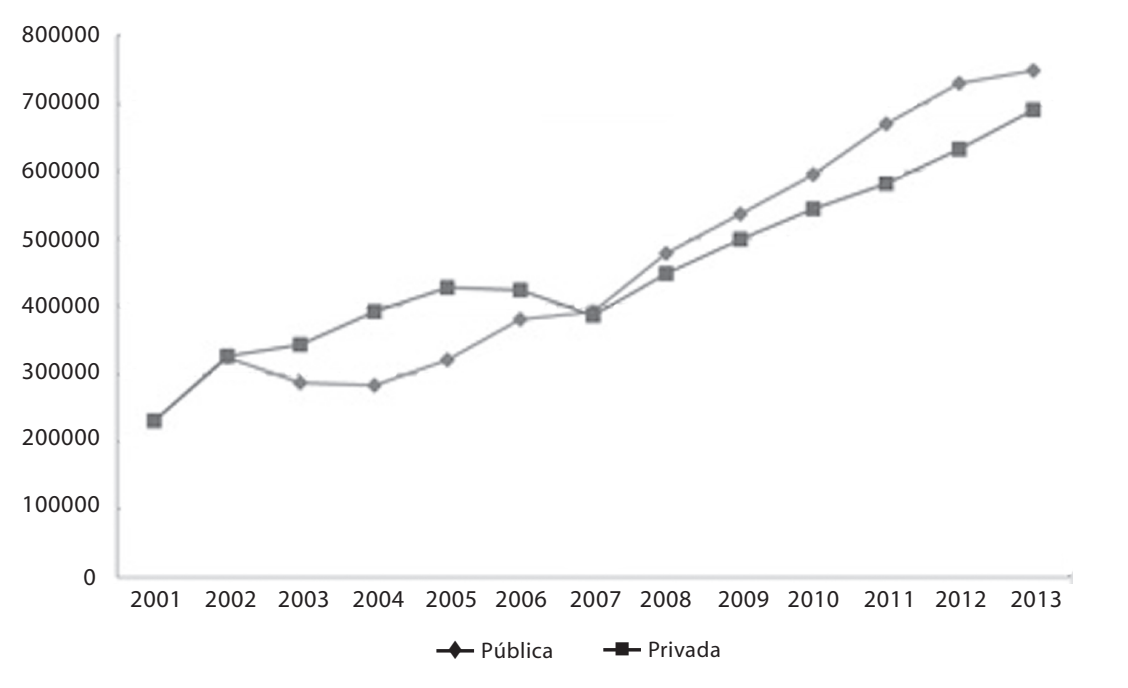

Fonte: Brasil (2014a).

$\mathrm{Na}$ análise dos censos escolares entre 2001 e 2013 (Gráfico 1), foi possível observar que, em 2001, as redes públicas e privadas possuíam, basicamente, o mesmo número de matrículas (231 mil nas escolas públicas e 230 mil na rede privada). Entre os anos de 2002 e 2006, houve um crescimento das matrículas nas instituições privadas, que a partir de 2007 sofreu uma inversão com o forte aumento das matrículas no setor público, especialmente das redes estaduais e federal, que em 2011 passaram a responder por $53,5 \%$ das matrículas. A partir do censo de 2012, observou-se uma retomada de aproximação da rede privada, chegando a responder por $48 \%$ das matrículas em 2013.

O aumento no quantitativo de matrículas realizadas refletiu-se, também, na ampliação do quantitativo de instituições de ensino. Contudo, a iniciativa privada, com 2.730 unidades, ainda detinha 59,6\% dos estabelecimentos de educação profissional, enquanto o segmento público, com 1.849 unidades, respondia por 40,4\% no cenário nacional. Esses dados, associados à relação média entre matrículas e unidades de ensino por dependência administrativa, 
puderam demonstrar uma capilaridade da iniciativa privada, com escolas menores, e a opção por escolas de médio e grande portes pelo setor público.

Essa expansão, conforme dados disponibilizados pelo Inep (Brasil, 2014a), ocorreu a partir de 2003 com um significativo crescimento da rede federal, que chegou, em 2013, a 467 unidades em 393 municípios, com perspectivas de atingir 562 unidades até o final de 2015. Se comparada com o crescimento entre os anos de 1909 e 2002, onde foram construídas 140 escolas técnicas em 118 municípios (Brasil, 2014b), a rede federal, de acordo com a projeção do MEC, alcançaria a média de 38 unidades novas por ano no período entre 2003 e 2015. Esses dados demonstraram o expressivo investimento realizado para ampliação das redes, principalmente a partir de 2007, e o potencial de crescimento e da demanda existente nessa modalidade de educação no país

Os dados analisados na pesquisa refletiram as políticas de educação de três governos: Fernando Henrique Cardoso (1994 a 2002), Luiz Inácio Lula da Silva (2003 a 2010) e os três primeiros anos de Dilma Rousseff (2011 a 2013), sendo relevante ressaltar que a realização de políticas de apoio à educação profissional, durante o governo do presidente Lula, provocaram a expansão da rede federal de ensino.

Os resultados das políticas de expansão das escolas federais, implementadas na gestão do Partido dos Trabalhadores, ficaram evidentes quando se compararam as matrículas na rede federal de educação profissional entre os três governos. De acordo com o censo escolar de 2003, ainda sob efeito do período do governo de Fernando Henrique, foram registradas 79 mil matrículas nas escolas federais; em 2008, durante o segundo mandato do presidente Lula, o censo escolar registrou 109 mil matrículas. Esse processo de crescimento continuou no primeiro governo Dilma, quando o censo escolar de 2013 apontou 228 mil alunos matriculados nos cursos de educação profissional. Em síntese, em dez anos o quantitativo de matrículas, basicamente, triplicou na rede federal de educação profissional.

Essa expansão de matrículas na rede federal ocorreu a partir do processo de criação dos institutos federais de educação, ciência e tecnologia. Assim, no período da pesquisa (2003-2013), enquanto as matrículas na rede federal triplicaram, na rede privada o crescimento foi de aproximadamente $115 \%$, passando de 324 mil para 691 mil no mesmo período.

Os dados apresentados pelo Inep podem significar a materialização das políticas públicas direcionadas à profissionalização, sendo necessário avaliar a efetividade social ou o impacto dessas políticas em cada região ou localidade. Pode-se, todavia, considerar que a rede federal de educação profissional vem respondendo, positivamente, ao processo de expansão das unidades de ensino pelo país.

No entanto, a ampliação dos cursos não garante a qualidade do ensino, portanto mais análises e debates sobre o tema precisam ser realizados, espe- 
cialmente na área da saúde, pois no Brasil convivem tipos diferentes de educação profissional em saúde. Juntamente com um ensino técnico-profissional, de duração mais longa, em escolas técnicas que visam formar profissionais capazes de enfrentar as mudanças que ainda surgirão, mantém-se um ensino de visão taylorista, o qual objetiva atender às necessidades imediatas do mercado. Com isso, continua a existir uma miríade de cursos de atualização, reciclagem, aperfeiçoamento ou outra denominação equivalente, alguns até cognominados como técnicos, visando preparar profissionais de maneira rápida e com baixo custo, mas de qualidade e eficácia duvidosas.

O que a sociedade deve exaltar, positivamente, é o fato de que o Brasil vem passando por transformações sociais, principalmente a partir do final do século XX, associadas a uma mudança na concepção de trabalho e de formação, com influência nas políticas norteadoras da educação e da saúde.

\section{A educação profissional em saúde}

A educação profissional em saúde vem apresentando números expressivos, especialmente no segmento privado, sendo a área com o maior crescimento progressivo no número de matriculados, que saiu dos 174 mil alunos em 2003 para 314 mil em 2013, de acordo com o censo da educação básica, divulgado em 2014 pelo Inep (Brasil, 2014a). É um significativo crescimento de $80 \%$, mesmo considerando que o censo abrangeu, além dos cursos na área profissional da saúde, o de ambiente e segurança.

$\mathrm{Na}$ área da saúde, o cenário da educação profissional tem apresentado os melhores índices de matrículas. No primeiro censo da educação profissional, realizado em 1999 (Brasil, 2014a), 11,4\% das matrículas situavam-se na área da saúde; em 2013, correspondiam a 21,8\%. A área da saúde manteve, basicamente, o mesmo ritmo de crescimento, mesmo após a separação dos cursos da área profissional do eixo segurança, a partir do censo de 2012, do eixo saúde e ambiente.

O importante é que o processo de expansão das escolas e, consequentemente, das matrículas, especialmente na área da saúde, não ocorra sem um processo de reflexão que considere a qualidade do ensino ministrado e da infraestrutura disponibilizada. A sociedade não deve aceitar nem comemorar a expansão da educação profissional como um ganho socioeducacional, especialmente sem antes refletir sobre a qualidade dos cursos oferecidos.

Embora ainda não sejam foco de avaliações externas, as instituições de educação profissional, principalmente da área da saúde, devem buscar desenvolver, internamente, uma cultura de avaliação dos seus cursos, especialmente por formarem profissionais que lidam com a vida humana. São cursos nos quais a ausência de experiências práticas ou a interpretação 
incorreta de um conceito podem causar muito mais do que um prejuízo material ou um atraso de cronograma, pois seus egressos terão, em suas mãos, a responsabilidade de cuidar de algo muito precioso para todos nós - a saúde.

A avaliação institucional, quando voltada aos cursos de educação profissional, surge como ferramenta de gestão que possibilita a tomada de decisões e o desenvolvimento de estratégias - e que não só contribui para o processo de diferenciação dos serviços oferecidos, mas também conduz ao aperfeiçoamento das vias de interação com a sociedade. São desafios intimamente relacionados às questões operacionais e políticas da instituição que precisam ser vencidos para que a educação profissional foque a qualidade nos cursos oferecidos e, consequentemente, na formação dos profissionais (Boanafina, 2009).

Não é demais mencionar que, com o advento da regulamentação das profissões de nível técnico, em particular da saúde, exige-se, nos concursos, comprovação escolar da habilitação, o que só fez aumentar a demanda institucional e a necessidade social que envolve a formação de quadros técnicos. Especificamente na área da saúde, as peculiaridades que caracterizam a formação de profissionais para o setor são complexas, pois reúnem um conjunto de variáveis e envolvem diferentes áreas de conhecimento. Dessa forma, conhecer o processo de expansão das instituições de formação dos profissionais de nível médio em saúde ajuda no debate, com a sociedade, sobre a prospecção e o direcionamento de recursos públicos, assim como na criação de elos com as políticas de atenção à saúde em cada localidade atendida pelas escolas.

Nessa perspectiva, emerge também a discussão sobre um currículo básico nacional para os cursos na área da saúde que objetive, essencialmente, a formação de profissionais envolvidos com os problemas prioritários de saúde e seus determinantes no Brasil - uma formação mais humanista direcionada para o entendimento do processo saúde-doença e das formas de intervenção e cuidado na busca pela qualidade de vida.

\section{A saúde na rede federal de educação profissional}

O ano de 2005 tornou-se referência para análise da expansão da rede federal devido à alteração do parágrafo $5^{\circ}$ do art. $3^{\circ}$ da lei n. 8.948, de 8 de dezembro de 1994 (Brasil, 1994), que limitava a expansão da oferta de educação profissional, e à aprovação de crédito adicional, no valor de R 57 milhões, destinado ao desenvolvimento da educação profissional (lei n. 11.249, de 23/12/2005) (Brasil, 2005).

A partir de 2008, com a promulgação da lei n. 11.892/2008 (Brasil, 2008), a rede federal passou a ser composta por centros federais de educação tecno- 
lógica, escolas técnicas e agrotécnicas federais, além dos recém-criados institutos federais de educação, ciência e tecnologia (IFs). Estes últimos, inclusive, podendo atuar em todos os níveis e modalidades da educação profissional.

Nessa perspectiva, a rede federal passou de 147 estabelecimentos em 2005, que representava 4,5\% do total das 3.294 instituições de educação profissional no país, para 467 em 2013, passando a representar 8,8\% do total das 5.261 instituições.

Atualmente, todos os estados brasileiros e o Distrito Federal possuem unidades da rede federal de educação profissional. Os dados disponibilizados pelo Inep indicaram que, nos últimos anos, a ampliação da rede federal foi significativa na região Nordeste, passando de 52 unidades de ensino em 2005 para 146 em 2013 (Tabela 1). Essa região apresentou o maior quantitativo de institutos federais (135), o que caracterizou, no período analisado, um forte investimento do governo federal no fortalecimento de políticas de expansão da rede federal para regiões fora do eixo Sul-Sudeste.

Tabela 1

Distribuição e total das unidades de ensino que formam a rede federal de educação por região no Brasil - Censo escolar 2013

\begin{tabular}{lcccccc}
\hline Unidade de ensino/região & Centro-Oeste & Nordeste & Norte & Sudeste & Sul & $\begin{array}{c}\text { Total de unidades } \\
\text { Brasil }\end{array}$ \\
\hline Instituto federal/campus & 41 & 135 & 45 & 94 & 75 & 41 \\
Cefet/campus & 0 & 0 & 0 & 17 & 0 & 0 \\
Escola técnica & 0 & 5 & 3 & 5 & 0 & 0 \\
Outros (*) & 1 & 6 & 1 & 22 & 17 & 1 \\
Total por região & 42 & 146 & 49 & 138 & 92 & 42 \\
\hline
\end{tabular}

Fonte: Brasil (2014a)

(*) Universidade tecnológica, colégios, centros de ensino.

As regiões Centro-Oeste, Nordeste e Norte, juntas, reuniam 50,7\% das unidades da rede federal de educação profissional, enquanto o eixo SulSudeste, que em 2005 respondia por 51 \% das 147 unidades de ensino, passou para 49,3\% em 2013 (Brasil, 2014a).

Das 467 unidades de ensino da rede federal de educação, apenas 51 (ou 10,9\%) ofereciam cursos na área da saúde. Ao se considerar a distribuição dessas unidades por região, o Centro-Oeste detinha o menor percentual, com apenas 4,8\% das escolas federais com cursos na área da saúde. Na extremidade oposta veio a região Norte, com 18,4\% das suas instituições, seguida pela região Sudeste, com 14,5\%; pela Sul, com 9,8\%; e pela Nordeste, com 7,5\% (Tabela 2). 
Tabela 2

\begin{tabular}{|c|c|c|c|c|c|}
\hline \multirow[t]{2}{*}{ Região } & \multirow{2}{*}{$\begin{array}{l}\text { Unidades da } \\
\text { rede federal } \\
\text { de educação }\end{array}$} & \multicolumn{2}{|c|}{$\begin{array}{l}\text { Unidades da rede federal } \\
\text { de educação com cursos } \\
\text { na área da saúde }\end{array}$} & \multicolumn{2}{|c|}{$\begin{array}{c}\text { Unidades da rede federal de } \\
\text { educação com curso técnico } \\
\text { em enfermagem }\end{array}$} \\
\hline & & $\mathrm{n}$ & $\%$ & $\mathrm{n}$ & $\%$ \\
\hline Centro-Oeste & 42 & 2 & 4,8 & 2 & 4,8 \\
\hline Nordeste & 146 & 11 & 7,5 & 9 & 6,2 \\
\hline Norte & 49 & 9 & 18,4 & 3 & 6,1 \\
\hline Sudeste & 138 & 20 & 14,5 & 17 & 12,3 \\
\hline Sul & 92 & 9 & 9,8 & 5 & 5,4 \\
\hline Total & 467 & 51 & 10,9 & 36 & 7,7 \\
\hline
\end{tabular}

Fonte: Brasil (2014a)

Os dados apontaram para a tendência de concentração dos cursos da área de saúde em polos econômicos, nos grandes centros populacionais, onde se concentram maior quantidade de serviços de saúde e, consequentemente, maior oferta de trabalho para esses profissionais.

O curso técnico em enfermagem, fundamental na formação de profissionais que lidam com a manutenção da vida, se torna uma referência para a análise da dispersão dos cursos da área da saúde vinculados à rede federal de educação no Brasil. Considerando-se o total das 467 unidades de ensino, apenas 36 (ou 7,7\%) ofereciam essa habilitação profissional (Tabela 2).

Ao se mapear o quantitativo das unidades por região, observou-se a centralização da oferta de cursos técnicos em enfermagem no eixo formado pelos estados das regiões Sul e Sudeste - as quais, juntas, dispunham de 22 $(17,7 \%)$ - e um grande vazio na região Centro-Oeste, com somente duas unidades dentre as 36 de ensino no Brasil (Tabela 2).

A falta de foco do investimento em profissionais e em assistência à saúde nas regiões mais carentes representa, no mínimo, uma ausência de planejamento ou de integração das ações dos ministérios da Educação e da Saúde. Essa aparente falta de 'sintonia ministerial' vem inviabilizando uma intervenção do Estado mais direcionada a locais com demandas por profissionais de saúde historicamente não atendidas, especialmente nas regiões Norte e Nordeste - intervenção que viabilizaria condições de acesso à educação e à saúde para essa população.

Há, sim, uma enorme diferença entre a demanda por profissionais e a oferta dos cursos da área da saúde. Em todas as outras áreas, a formação/absorção de mão de obra depende, irremediavelmente, de especificidades locais, vocações regionais ou capacidade instalada. Já na área da saúde, cidadãos de todos os lugares - dos mais cosmopolitas aos mais afastados dos grandes 
centros - necessitam, em todas as etapas da vida, encontrar profissionais aptos, dispostos e disponíveis para atendê-los.

Assim, defendemos a tese de que, especificamente na área da saúde, o Estado deva assumir o protagonismo na formação de profissionais, de modo a alinhar as ações de qualificação à expansão da rede de assistência pública, investindo na criação de cursos que atendam as áreas com baixo grau de desenvolvimento social e econômico, especialmente as regiões que não dispõem de condições mínimas de acesso aos serviços básicos de saúde.

O relatório Demografia médica no Brasil, de Scheffer, Biancarelli e Cassenote (2013), traz uma contribuição ao presente estudo ao associar a concentração de médicos à presença de outros profissionais e de estabelecimentos de saúde. Segundo o relatório,

Regiões com maior número de médicos também contam com maior contingente de dentistas, de enfermeiros, de técnicos de enfermagem e de auxiliares de enfermagem. Da mesma forma, o estudo mostra que a presença médica está diretamente relacionada à capacidade instalada dos serviços de saúde (Scheffer, Biancarelli e Cassenote, 2013, p. 109).

Ainda de acordo com o relatório, no Brasil há 330.928 postos de trabalho ocupados por técnicos de enfermagem; 317.420, por auxiliares de enfermagem; e 636.017, por médicos. Esses dados indicam que existe um total de 1,92 posto de médico para cada posto de trabalho de técnico de enfermagem, porém a relação varia entre os estados.

São Paulo, por exemplo, possui $28,96 \%$ dos postos de trabalho médico e $16,53 \%$ dos de técnicos de enfermagem. No extremo oposto, estão os estados da região Norte, que, juntos, possuem menos de 4,63\% dos postos de trabalho médico e $8,66 \%$ dos de técnicos de enfermagem (Scheffer, Biancarelli e Cassenote, 2013).

Os técnicos e os auxiliares de enfermagem são os profissionais mais numerosos quando se compara com os médicos. São Paulo, estado que soma maior número de médicos, tem 3,37 médicos por técnico de enfermagem, contra uma média nacional de 1,92. Três estados, todos do Norte, têm menos de um técnico de enfermagem para cada médico, o que, nesse caso, revela carência desses dois profissionais (Scheffer, Biancarelli e Cassenote, 2013, p. 111).

O relatório desenvolvido pelo Conselho Federal de Medicina aponta para a média de 2,5 médicos por mil habitantes nas regiões Sul e Sudeste, enquanto nas regiões Norte e Nordeste essa média cai para menos de um médico por mil habitantes, "índices comparáveis a países africanos" (Scheffer, Biancarelli e Cassenote, 2011, p. 31). Ainda segundo o estudo, 
Regiões menos desenvolvidas, mais pobres e interiores de estados com grandes territórios e zonas rurais extensas têm, sabidamente, maior dificuldade para fixar e atrair profissionais médicos (Scheffer, Biancarelli e Cassenote, 2011, p. 31).

Embora não aborde a realidade da equipe de apoio aos médicos, o estudo do CFM ratificou os dados do IBGE (2010) quando o instituto identificou que, no período de 2005 a 2009, houve um crescimento de $26,9 \%$ nos postos de trabalho de nível superior na área da saúde e de 105,1\% nos de técnicos de enfermagem. Contudo, o número de postos de trabalho médico e, consequentemente, dos demais profissionais de saúde do país não seguiu, na mesma proporção, sua distribuição populacional, ou seja,

enquanto $23,7 \%$ da população vivia nas capitais em 2009, 40,2\% dos postos médicos estavam localizados neste local, o que equivale à relação de 5,6 postos médicos por 1.000 habitantes nas capitais e 2,6 postos médicos por 1.000 habitantes nos demais Municípios do País. Em 2005, o retrato era bastante parecido, o indicador do número de posto de trabalho médico na capital era de 5,1 e nos demais Municípios de 2,2 (Instituto Brasileiro de Geografia e Estatística, 2010, p. 46).

Os dados de 2012 da ANS, apresentados pelo IBGE (2013), corroboram os demais estudos já citados, apontando para o fato de que, proporcionalmente, a população coberta por planos de saúde estava concentrada, com $64 \%$ dos planos, na região Sudeste. Ainda segundo o IBGE (2013), as mudanças demográficas vêm demandando o aumento de investimento público em saúde, fundamentalmente na ampliação da cobertura do SUS em regiões carentes e afastadas dos grandes centros urbanos, que não contam com os planos de saúde.

Ao se associarem os dados disponibilizados pelos dois relatórios, de 2011 e 2013, aos do IBGE, observou-se que existe uma relação entre concentração de médicos e de técnicos e auxiliares de enfermagem, com maior agrupamento desses profissionais nas capitais dos estados das regiões Sul e Sudeste, enquanto nos estados das regiões Nordeste e Norte ocorre, justamente, a menor concentração.

Em certa medida, a implementação de cursos da área de saúde em escolas federais segue o mesmo padrão, com alta concentração de unidades nas regiões Sul e Sudeste e baixa concentração nas regiões Norte, Nordeste e Centro-Oeste. No estado de Minas Gerais, por exemplo, existem 51 unidades da rede federal de educação; em 15 são oferecidos o curso técnico em enfermagem, incluído um a distância no Instituto Federal de Juiz de Fora. Nos estados do Acre, Amapá, Alagoas, Sergipe, Mato Grosso, Mato Grosso de Sul e no Distrito Federal, no período analisado, não havia oferta de cursos técnicos na área de saúde nas unidades da rede federal de educação (Brasil, 2014a). 


\section{Considerações finais}

O estudo apresentado neste artigo apontou um aparente descolamento entre as políticas de expansão da rede federal de educação profissional na área da saúde e as demandas do Ministério da Saúde para suprir a carência de desses profissionais de nível médio em área onde há demanda por equipe de apoio e de técnicos. Essa visível ausência de sintonia entre demanda e formação de profissionais de nível médio pode gerar impactos negativos em programas do ministério, tais como 'Mais saúde' e 'Mais médicos', que necessitam de profissionais de nível médio como apoio.

As análises deste estudo registraram, também, o fato de que a rede federal não vem priorizando a expansão da oferta de cursos da área da saúde. De acordo com o Inep (2012), na rede federal os esses cursos não aparecem entre os dez com maior número de matrículas e representam menos de 2,0\% do total de 1,2 milhão de matrículas. Entretanto, como já dissemos, a área da saúde é a que apresenta historicamente, na educação profissional, o maior número de matrículas. Posto isso, concluiu-se que a maior parte da oferta na área origina-se na iniciativa privada, com alguma oferta pontual, fruto de iniciativas isoladas, de estados e municípios - todos sem nenhuma responsabilidade para com o país e sua população como um todo.

O comportamento das matrículas e o processo de expansão dos estabelecimentos da rede federal refletiram, além das variáveis relacionadas à demografia e à diversidade econômica de cada região, as políticas educacionais definidas pelo MEC para responder às demandas por cursos. O contínuo crescimento no quantitativo de matrículas pode significar a materialização das políticas públicas direcionadas à profissionalização, porém é necessário avaliar a efetividade social ou o impacto dessas políticas em cada região ou localidade, especialmente para a melhoria nos serviços de atenção à saúde.

Os dados apresentados indicaram que a rede federal de educação profissional não está cumprindo, plenamente, sua função social de formação estratégica de profissionais sem se submeter aos interesses do 'mundo do trabalho'. Espera-se que a rede federal de educação profissional não utilize o mesmo modelo de implantação de novas escolas/cursos da iniciativa privada ou dos interesses locais (representados pelas redes estaduais e municipais de formação). O MEC deve repensar a lógica da oferta de cursos, privilegiando aqueles territórios/populações esquecidos pelas outras redes. No caso particular da saúde, os dados demonstraram que as unidades federais são insuficientes para atenderem à demanda da sociedade, especialmente nas regiões Norte, Nordeste e Centro-Oeste e, particularmente, fora dos grandes centros urbanos.

Conhecer a realidade regional de formação dos profissionais de nível médio na área da saúde ajuda na prospecção e no direcionamento de recursos, 
especialmente do governo federal, destinados à expansão dos cursos e à ampliação das matrículas, em concordância com as políticas de atenção à saúde. Esse direcionamento de recursos implica, para além da expansão dos cursos, incrementar a presença do Estado na formulação e na implementação de ações que visem à retenção de talentos e à valorização dos docentes e dos profissionais de saúde nas regiões com assistência mais deficitária.

Entendemos que cabe ao $\mathrm{MEC}$, em articulação com o Ministério da Saúde, o papel de protagonista na formação e qualificação de profissionais que venham atender, prioritariamente, as áreas mais carentes de atenção primária à saúde - o que significa estabelecer um planejamento estratégico social que priorize os estados mais carentes de recursos humanos na área da saúde, com investimento em cursos direcionados a atender, de forma regionalizada, as demandas da população por vigilância e assistência.

\section{Colaboradores}

Anderson Boanafina realizou a pesquisa bibliográfica/documental, fez o levantamento, tratamento e análise de dados, além da composição do texto. Mônica Wermelinger também realizou a pesquisa bibliográfica/documental, fez a análise de dados e a composição do texto. Lilian Boanafina realizou as pesquisa bibliográfica/documental e a composição do texto.

Resumen La educación profesional debe ser pensada e implementada como una acción estraté-gica, considerando las potencialidades tecnológicas locales y regionales, realzando su interacción con el mundo del trabajo y, fundamentalmente, con la sociedad local, con la función primordial de formación ciudadana y preparando al joven para ser un agente activo en los procesos de desarrollo social, económico y cultural. A partir de esta premisa, el presente artículo propone un análisis de las matrículas en la educación profesional, destacando datos e información relevantes para la comprensión del actual escenario de la formación de recursos humanos en el área de la salud promovida por instituciones federales en Brasil. El estudio señala una aparente divergencia entre las políticas de expansión de la red federal de educación profesional en el área de la salud y las demandas del Ministerio de Salud para satisfacer la carencia de profesionales de nivel medio en salud, especialmente en las regiones Norte, Nordeste y Centro-Oeste y, particularmente, fuera de los grandes centros urbanos.

Palabras clave educación profesional; instituciones federales; salud. 


\section{Notas}

1 Fundação Oswaldo Cruz, Casa de Oswaldo Cruz, Rio de Janeiro, RJ, Brasil.

<aboanafina@fiocruz.br>

Correspondência: Rua das Tulipas, 241, apto. 403, Vila Valqueire, CEP 21330-400, Rio de Janeiro, RJ, Brasil.

2 Instituto Federal de Educação, Ciência e Tecnologia, Rio de Janeiro, RJ, Brasil.

$<$ lilian.boanafina@ifrj.edu.br>

3 Fundação Oswaldo Cruz, Escola Nacional de Saúde Pública Sergio Arouca, Rio de Janeiro, RJ, Brasil.

$<$ monicaw@fiocruz.br $>$

4 Fonte dos dados: Microdados do Censo da Educação Básica (1999-2014), MEC/Inep, disponíveis para download em: <http://portal.inep.gov.br/basica-levantamentos-acessar> Utilizou-se a mesma fonte para obtenção e tratamento dos dados apresentados referentes aos quantitativos de matrículas, escolas/instituições e cursos, inclusive na elaboração de todas as tabelas e do gráfico. Na extração e tratamentos dos dados, a pesquisa utilizou o software Statistical Package for the Social Sciences for Windows (SPSS).

\section{Referências}

BOANAFINA, Anderson. Autoavaliação de curso: uma proposição metodológica para a educação profissional. Dissertação (Mestrado em Avaliação) - Fundação Cesgranrio, Rio de Janeiro, 2009. Disponível em: <www. dominiopublico.gov.br/pesquisa/DetalheObra Form.do?select_action $=\&$ co_obra $=203006>$. Acesso em: 15 abr. 2014.

BRASIL. Decreto n. 7.566, de 23 de setembro de 1909. Cria nas capitais dos Estados da República Escola de Aprendizes Artífices, para o ensino profissional primário e gratuito. Rio de Janeiro: Diário Oficial da União, Brasília, DF, Seção 1, p. 6.975, 26 set. 1909. Disponível em: <www2.camara.leg. br/legin/fed/decret/1900-1909/decreto-756623-setembro-1909-525411-publicacaooriginal1-pe.html>. Acesso em: 21 jun. 2014.
BRASIL. Decreto n. 4.127, de 25 de fevereiro de 1942. Estabelece as bases de organização da rede federal de estabelecimentos de ensino industrial. Diário Oficial da União, Brasília, DF, Seção 1, p. 2.957, 27 fev. 1942. Disponível em: <www2.camara.leg.br/legin/ fed/declei/1940-1949/decreto-lei-4127-25fevereiro-1942-414123-publicacaooriginal1-pe.html>. Acesso em: 17 abr. 2014.

BRASIL. Senado Federal. Lei n. 8.948, de 8 de dezembro de 1994. Dispõe sobre a instituição do Sistema Nacional de Educação e dá outras providências. Disponível em: <www. planalto.gov.br/ccivil_03/leis/L8948.htm> . Acesso em: 3 out. 2013.

BRASIL. Lei n. 9.394, de 20 de dezembro de 1996. Estabelece as diretrizes e bases da 
educação nacional. Diário Oficial da União, Brasília, DF, 23 dez. 1996. Disponível em: $<$ www.planalto.gov.br/ccivil_03/leis/L9394. htm>. Acesso em: 15 fev. 2014.

BRASIL. Decreto n. 2.208, de 17 de abril de 1997. Regulamenta o parágrafo $2^{\circ}$ do art. 36 e os art. 39 a 42 da lei n. 9.394, de 20 de dezembro de 1996, que estabelece as diretrizes e bases da educação nacional. Diário Oficial da União, Brasília, DF, p. 7.760, 18 abr. 1997. Disponível em: <www.planalto. gov.br/ccivil_03/decreto/D2208.htm>. Acesso em: 15 fev. 2014.

BRASIL. Decreto n. 5.154, de 23 de julho de 2004. Regulamenta o $\S 2^{\circ}$ do art. 36 e os arts. 39 a 41 da lei n. 9.394, de 20 de dezembro de 1996, que estabelece as diretrizes e bases da educação nacional e dá outras providências. Diário Oficial da União, Brasília, DF, 26 jul. 2004. Disponível em: <www.planalto.gov.br/ccivil_03/_ato20042006/2004/decreto/d5154.htm>. Acesso em: 15 fev. 2014.

BRASIL. Lei n. 11.249, de 23 de dezembro de 2005. Abre aos Orçamentos Fiscais e da Seguridade Social da União, em favor dos Ministérios da Ciência e Tecnologia, da Educação, da Cultura e do Esporte e dá outras providências. Diário Oficial da União, Brasília, DF, 23 de dezembro de 2005. Edição Extra. Disponível em: <www.planalto.gov. br/ccivil_03/_Ato2004-2006/2005/Lei/ L11249.htm>. Acesso em: 10 mar. 2014.

BRASIL. Lei n. 11.892, de 29 de dezembro de 2008. Institui a Rede Federal de Educação Profissional, Científica e Tecnológica, cria os Institutos Federais de Educação, Ciência e Tecnologia e dá outras providências. Diário Oficial União, Brasília, DF, Seção 1, 30 dez. 2008. Disponível em: <www. planalto.gov.br/ccivil_03/_ato2007-2010/2008/ lei/111892.htm>. Acesso em: 06 mar. 2014.

BRASIL. Ministério da Educação. Instituto Nacional de Estudos e Pesquisas Educacionais Anísio Teixeira (Inep). Microdados do Censo Escolar da Educação Básica 1999-2014. Brasília, DF, 2014a. Disponível em: < http:// portal.inep.gov.br/basica-levantamentosacessar> . Acesso em: 21 mar. 2014.

BRASIL. Ministério da Educação. Expansão da Rede Federal. 2014b. Disponível em: $<$ http://redefederal.mec.gov.br/expansaoda-rede-federal $>$. Acesso em: 18 out. 2014

CONSELHO NACIONAL DE EDUCAÇÃO. Câmara de Educação Básica. Parecer CNE/CEB n. 16, de 5 de outubro de 1999. Diretrizes Curriculares Nacionais para a Educação Profissional de Nível Técnico. Diário Oficial da União, Brasília, DF, 26 nov. 1999a. Disponível em: <http://portal.mec.gov.br/cne/ arquivos/pdf/1999/pceb016_99.pdf $>$. Acesso em: 12 jan. 2014.

CONSELHO NACIONAL DE EDUCAÇÃO. Câmara de Educação Básica. Resolução CNE/CEB n. 4, de 8 de dezembro de 1999. Institui as Diretrizes Curriculares Nacionais para a Educação Profissional de Nível Técnico. Diário Oficial da União, Brasília, DF, Seção 1, p. 229, 22 dez. 1999b. Disponível em: <http://portal.mec.gov.br/dmdocuments/ rceb004_99.pdf>. Acesso em: 12 jan 2014.

DELUIZ, Neise. A globalização econômica e os desafios à formação profissional. Boletim Técnico Senac, Rio de Janeiro, v. 22, n. 2, p. 15-21, maio-ago. 1996.

FRIGOTTO, Gaudêncio; CIAVATTA, Maria; RAMOS, Marise. A política de educação profissional no governo Lula: um percurso histórico controvertido. Educação e Sociedade, Campinas, v. 26, n. 92, esp., p. 1.087-1.113, out. 2005a.

FRIGOTTO, Gaudêncio; CIAVATTA, Maria; RAMOS, Marise. A gênese do decreto n. 5.154/2004: um debate no contexto controverso da democracia restrita. Trabalho necessário, Niterói, ano 3, n. 3, p. 1-26, 2005 b. Disponível em: < http://forumeja.org.br/pf/sites/ forumeja.org.br.pf/files/CIAVATTAFRIGOTTO RAMOS.pdf $>$. Acesso em: 8 abr. 2014.

FONSECA, Celso S. História do Ensino Industrial no Brasil. Rio de Janeiro: Tipografia da Escola Técnica Nacional, 1961. 2v. 
GALEANO, Eduardo. As veias abertas da América Latina. Tradução de Galeno de Freitas. 25. ed. Rio de Janeiro: Paz e Terra, 1987. 307 p.

INSTITUTO BRASILEIRO DE GEOGRAFIA E ESTATÍSTICA (IBGE). Estatísticas da saúde: assistência médico-sanitária 2009. Rio de Janeiro: IBGE, 2010. Disponível em: <www. ibge.gov.br/english/estatistica/populacao/ condicaodevida/ams/2009/ams2009.pdf $>$. Acesso em: 2 jun. 2013.

INSTITUTO BRASILEIRO DE GEOGRAFIA E ESTATÍSTICA (IBGE). Sintese de indicadores sociais 2013: uma análise das condições de vida da população brasileira. Rio de Janeiro: IBGE, 2013. Disponível em: <http:// biblioteca.ibge.gov.br/visualizacao/livros/ liv66777.pdf>. Acesso em: $1^{\circ}$ jul. 2014.

KUENZER, Acácia. Ensino médio e profissional: as políticas do Estado neoliberal. 2. ed. São Paulo: Cortez, 2000.

MANFREDI, Silvia M. Educação Profissional no Brasil. São Paulo: Cortez, 2002.
MORALES-GOMEZ, Daniel A.; MOE, Judith A. Perspectivas sobre educación y trabajo. Cinterfor Boletin, Montevideo, vol. 110, maio, 1989. p. 135-155.

RAMOS, Marise. N. A pedagogia das competências: autonomia ou adaptação? São Paulo: Cortez, 2001.

SCHEFFER, Mario; BIANCARELLI, Aureliano; CASSENOTE, Alex. Demografia médica no Brasil: dados gerais e descrições de desigualdades. São Paulo: Conselho Regional de Medicina do Estado de São Paulo e Conselho Federal de Medicina, 2011.

SCHEFFER, Mario; BIANCARELLI, Aureliano; CASSENOTE, Alex. Demografia médica no Brasil. v. 2. São Paulo: Conselho Regional de Medicina do Estado de São Paulo e Conselho Federal de Medicina, 2013.

SCHWARTZMAN, Simon; BOMENY, Helena B.; COSTA, Vanda R. Tempos de Capanema. 2. ed. Rio de Janeiro: FGV Editora, Paz e Terra, 2000.

Recebido em 19/09/2014

Aprovado em 03/05/2015 